STUDI

FRANCESI

\section{Studi Francesi}

Rivista quadrimestrale fondata da Franco Simone

190 (LXIV | I) | 2020

Varia - fasc. I - gennaio-aprile 2020

\title{
GAËLLE BURG, La vogue du roman de chevalerie médiéval dans les imprimés renaissants: critique et prescription, in Prescription culturelle: avatars et métamorphoses
}

\author{
Ludmilla Dali
}

\section{OpenEdition}

Journals

Édition électronique

URL : https://journals.openedition.org/studifrancesi/22396

DOI : 10.4000/studifrancesi.22396

ISSN : 2421-5856

Éditeur

Rosenberg \& Sellier

Édition imprimée

Date de publication : 1 avril 2020

Pagination : 159

ISSN : 0039-2944

Référence électronique

Ludmilla Dali, « GAËLLE BURG, La vogue du roman de chevalerie médiéval dans les imprimés renaissants: critique et prescription, in Prescription culturelle: avatars et métamorphoses », Studi Francesi [En ligne], 190 (LXIV | I) | 2020, mis en ligne le 01 avril 2020, consulté le 02 août 2021. URL : http://

journals.openedition.org/studifrancesi/22396; DOI : https://doi.org/10.4000/studifrancesi.22396

Ce document a été généré automatiquement le 2 août 2021.

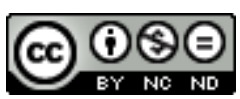

Studi Francesi è distribuita con Licenza Creative Commons Attribuzione - Non commerciale - Non opere derivate 4.0 Internazionale. 
GAËLLE BURG, La vogue du roman de chevalerie médiéval dans les imprimés renaissants: critique et prescription, in Prescription culturelle: avatars et métamorphoses

\author{
Ludmilla Dali
}

\title{
RÉFÉRENCE
}

GAËLLE BURG, La vogue du roman de chevalerie médiéval dans les imprimés renaissants: critique et prescription, in Prescription culturelle: avatars et métamorphoses, , Paris, Presses de l'ENSSIB, 2018, pp. 67-84.

L'avènement de l'imprimerie en France octroie ponctuellement à la littérature chevaleresque médiévale un second souffle. Cet article de Gaëlle Burg offre un panorama rigoureux et concis quant aux détractions, défenses, injonctions et potentiels bénéfices constitutifs de cette vogue renaissante, au prisme de ses acteurs pluriels. Dissociant un humanisme de la rupture à un autre de la continuité, G.B. se saisit ainsi $\mathrm{du}$ discours de certains de ses censeurs humanistes et moralistes, à l'instar de Montaigne, qui, du temps des premières réflexions théoriques sur le roman, décrient l'inutilité, le caractère hétéroclite voire obscène de ces «vieux romans» alors rattachés à une période d'obscurantisme. Dans cette dichotomie intrinsèque entre fonction récréative et morale, et en dépit de la mauvaise réputation dont il jouit, le roman de chevalerie médiéval se voit expressément réhabilité par Du Bellay, Peletier du Mans et Ronsard. Les prescriptions de ces partisans des «vieux romans» et de leurs héritiers renaissants appellent ainsi à l'assimilation et la transmission par l'imprimerie de ce qui constituera progressivement un patrimoine littéraire et linguistique national. L'analyse 
érudite de G.B. ne manque pas de faire valoir le rôle commercial et auctorial capital endossé par l'imprimeur-libraire, dont le discours prescriptif insiste sur l'envergure tant exemplaire que divertissante de ces remaniements renaissants. Corroboré par une recherche bibliographique substantielle, cet article permet de saisir avec pertinence l'ampleur de ces «antiquitez françoyes» comme jalons notables de l'histoire littéraire, culturelle et commerciale du roman, aux antipodes de l'idée traditionnelle de rupture abrupte entre «ténèbres gothiques» et humanisme. 